\title{
PLC AND SCADA BASED IRRIGATION SYSTEM TO MONITOR THE MOISTURE CONTENT OF AGRICULTURE FIELDS
}

\author{
Savitha T.C \\ Industrial Automation and Robotics \\ Department of Mechanical Engineering \\ Malnad college of Engineering, Hassan, Karnataka, \\ India
}

\begin{abstract}
The design of a programmable logic controller based system to control an automatic irrigation system. The system comprises of three modules: the programmable logic circuits, sensor system and the SCADA monitoring. The irrigation system composes of three samples, simulating three different agriculture fields. The humidity of each field is different from that of other fields according to the requirement of different plantation. It is controlled by two sensors for minimum and maximum humidity respectively. Each sample is irrigated by a separate valve. The valves are controlled by the PLC. If the maximum humidity is reached, the PLC turns off the concerned valve based on value fed by the concerned sample. When all samples have reached their respective maximum humidity, the PLC turns off the main pump. This project is proposed to overcome difficulties faced by the farmers in gaining more profit by increasing the productivity and reducing the consumption of water and electricity. Farmers will be able to monitor and control the irrigation system from one place with the help of SCADA (supervisory control and data acquisition) which does the controlling action through PLC (Programmable Logic Controller).
\end{abstract}

Keywords - PLC (Programmable logic controller), SCADA (Supervisory Control and Data Aquisition), Microcontroller (Arduino UNO), GSM Module, Relay card

\section{INTRODUCTION}

India is a monsoon land and basically depends on agriculture. Now a day's people are following the traditional procedures like canals from river, ground water well based system and rain water harvesting for agriculture purpose. For this reasons there will be a chance of getting shortage of water in many places of India. This is the common problem in Maharashtra. Around $33 \%$ of yield was spoiled by animals in India (A.B. Jirapure1 et al, 2018).
Around $70 \%$ of people depend on agriculture for their income. Most of the people mainly depend on manually operated irrigation. In present scenario these manually operated irrigation system is replaced by automated and semiautomated techniques (Karan Kansara et al, 2015).

Around $35 \%$ of farming land was consistently irrigated in the year 2010. Around $2 / 3^{\text {rd }}$ of cultivated land depend on monsoon by the Indian people. In recent years the old technology was replaced by modern methods to make improvements in food security, least depend on monsoon, increase the yield production and provide job opportunities. Dams are constructed for irrigation and supply drinking water and for the control of the flood and also to avoid droughts that will damage the agriculture.

In India the rainy season is limited for four months and the remaining eight months are almost dry so in these days irrigation is very difficult but in the month December and January some places of India may get some rainfall. Even during monsoon seasons the rainfall is very little at few parts of the country. These monsoons are undefinable because sometimes it is too early but sometimes it may be delayed so people face few problems in agriculture field.

Meanwhile irrigation helps the farmer so that people will not depend on the monsoon. In India the climate is not consistent and varied from region to region. Here monsoon are irregular in nature so most of them depend on irrigation. For Rabi crop, irrigation is must. These Rabi crops are grown up in winter season where the soil is almost dry.

High breed seeds can cultivate in any season but the yield of the crop depends upon the water. The irrigation facility mainly helps during dry season.

India is highly populated country around 1.37 billion of people, since the requirement of crop is very high from year to year. So, production of food crops depend on irrigation (G. Parameswaran et al, 2016). 


\section{International Journal of Engineering Applied Sciences and Technology, 2019 \\ Vol. 4, Issue 2, ISSN No. 2455-2143, Pages 201-205 \\ Published Online June 2019 in IJEAST (http://www.ijeast.com)}

\section{METHODOLOGY}

In this automatic irrigation system, the moisture content in the field is detected and according to that the fields are watered. There are three different agriculture fields in this system. The moisture content in each field is detected by moisture sensors present in the fields.

Once the moisture content is detected, the moisture content in three different fields is compared by the comparison instruction in the PLC. After comparing, the water pump will water the field which has the least water content. After that the remaining fields are watered based on their moisture levels. This complete system can be monitored and controlled from SCADA and mobile phone by using RFID technology.

The block diagram of the proposed voting system is as shown in the below figure 1 .

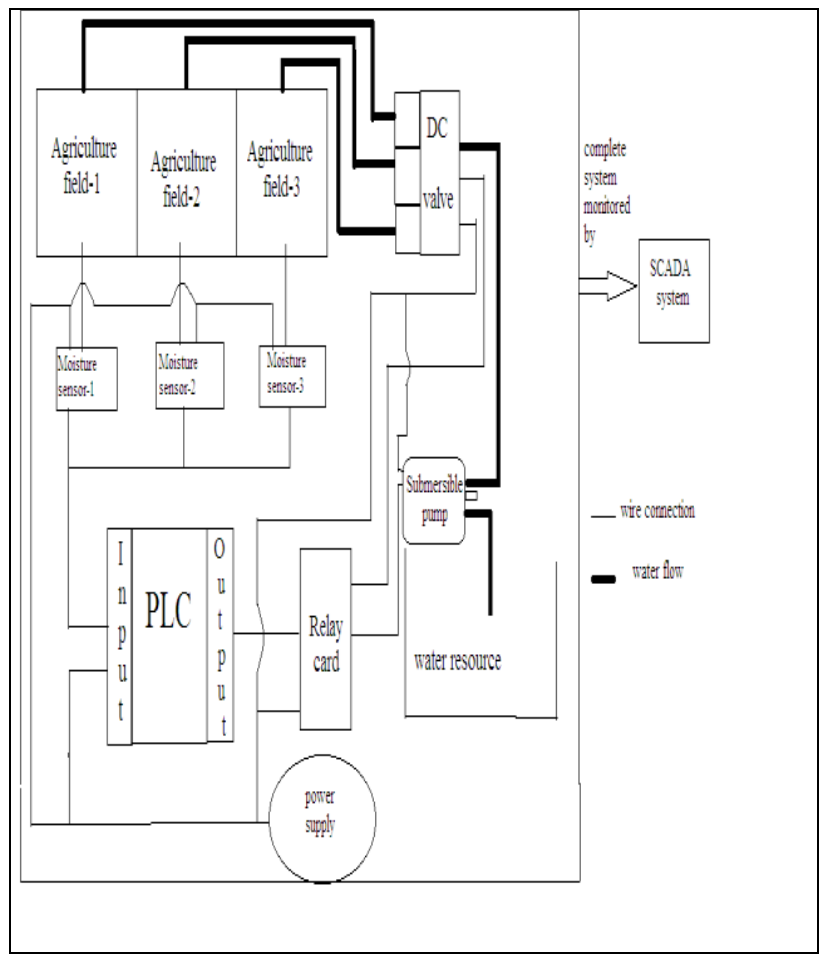

Fig -1: Block diagram of PLC and SCADA based automatic irrigation system

Hardware components are;
a. Delta PLC
b. Moisture sensors
c. Switch mode power supply (SMPS)
d. Relay card of $24 \mathrm{~V}$
e. Relay card of $5 \mathrm{~V}$

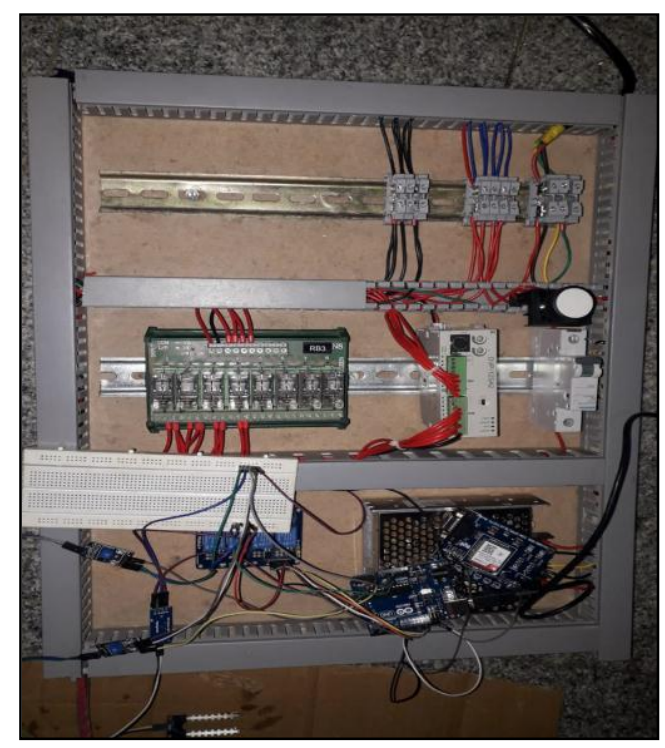

Fig -2: Working model of a Automatic irrigation system

\section{a. Delta PLC}

In this project PLC is used to control the process. This PLC is a compatible device where many controllers are combined. The PLC has analog processing and ladder processing; these programming process are quiet easy compare to other process. CPU unit is used to store the memory in PLC.

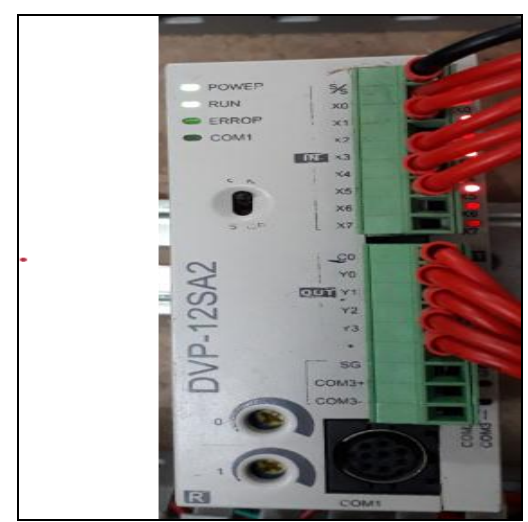

Fig -3: Delta PLC

b. Moisture sensor

Moisture sensor is used to check the moisture level in the soil. These moisture sensors are immersed in soil to monitor the moisture content in the soil. If the output given by the moisture sensor in a particular area is lesser than the set point parameter then PLC gives signal to the solenoid valve of that particular area and the valve gets open, if it is vice versa valve will be closed or the flow will be controlled. 


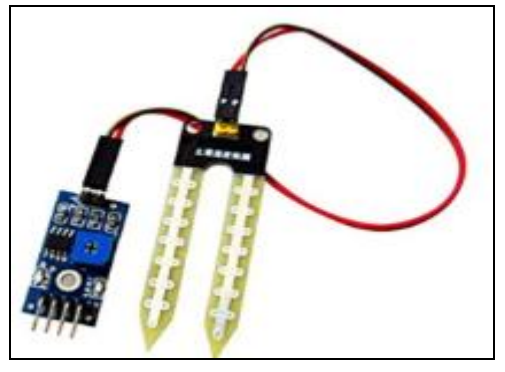

Fig -4: Moisture sensor

c. Switch mode power supply (SMPS)

In this project, it is used to convert $230 \mathrm{~V}$ AC to $24 \mathrm{~V} \mathrm{DC}$ because this PLC requires input voltage of $24 \mathrm{~V}$ DC as a power source.

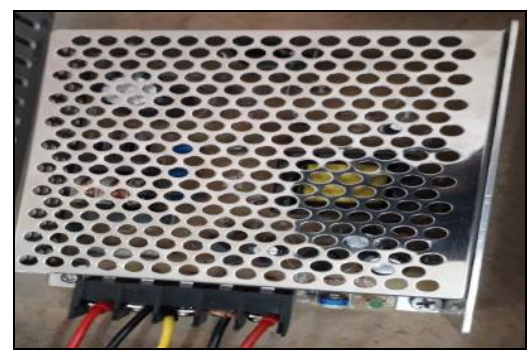

Fig -5: Switch mode power supply (SMPS)

\section{d. Relay card of $24 \mathrm{~V}$}

It is a protecting device in entire circuit system. Its function is to close and open circuits electromechanically and electronically. Here the input is $24 \mathrm{~V}$ and output is $12 \mathrm{~V}$. The input signal from PLC and output signal are send to motor to open and close of valve and also to submersible pump to pump the water.

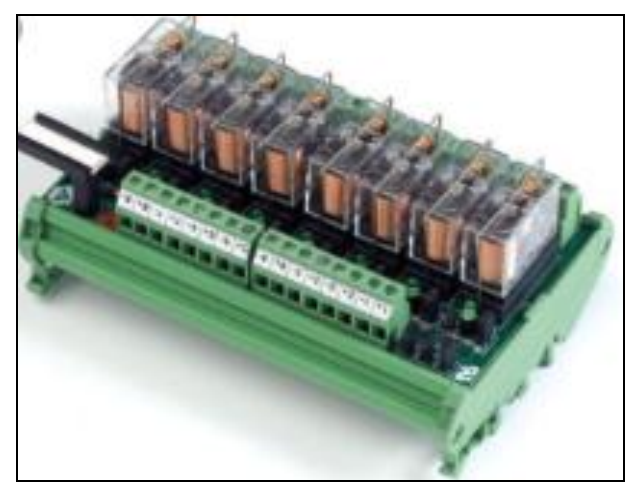

Fig -6: SCADA screen of the working model having less

\section{e. Relay card of $5 \mathrm{~V}$}

These relay card is also used as a step down voltage converter. Here the input is $12 \mathrm{~V}$ and output is $5 \mathrm{~V}$. Input signal is from relay card of $24 \mathrm{~V}$ and output signal is send to microcontroller.

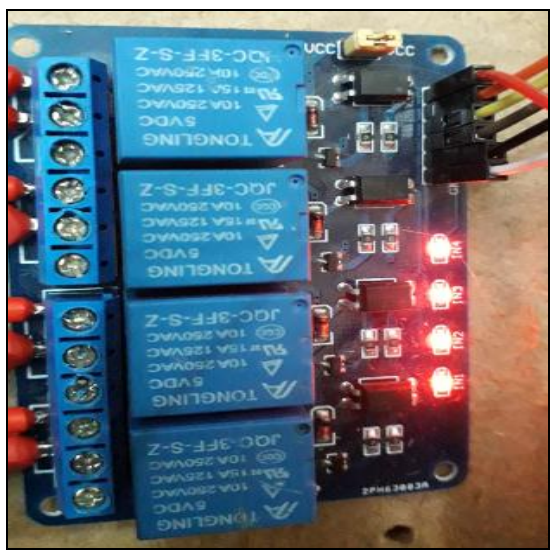

Fig -7: Relay card of 5V

Software tools are;

\section{a. KEPServerEX}

It acts as a single source of industrial automation data to all application. Its functions are monitoring, managing and controlling the various automation device and helps in interfacing of software.

\section{b. PLC programming}

PLC is a digital computer used for automation in industries. It is having multiple analog, digital inputs and output arrangement. When PLC receives the information from the field, it evaluates the information and sends the information to the different fields. The components of PLC are;
1. Input module
2. Power supply
3. Central Processing Unit (CPU)
4. Output module

A programmable automation controller (PAC) is a compact controller that combines the features and capabilities of a PCbased control system with that of a typical PLC. PACs are deployed in SCADA systems to provide RTU and PLC functions. 


\section{c. SCADA software}

In this project SCADA is used to monitor and control the whole process after designing and interfacing it with the PLC. It consists of

1. Supervisory computers

2. Remote terminal units

3. Communication infrastructure

The software used is Wonderware "InTouch". It provides a unified integrated view of all controls and information resources. This InTouch is having simplistic graphics to facilitate application builders to focus on creating meaningful content that will drive enterprise-wide operations productivity and cost savings. InTouch empowers operators to optimize their routine human interactions with industrial automation systems.

\section{EXPERIMENT AND RESULT}

In this irrigation system there are 3 fields and these fields moisture content are monitored by using moisture sensors. Once the moisture level is identified then these values are send to the microcontroller and it sends to GSM module further it send to relay card, based on that moisture value the microcontroller will helps that valve in which it should be $\mathrm{ON}$ and OFF first.

The PLC is programmed to check the moisture level in field which send it to relay card and the PLC helps to pump the water from tank and relay card helps in closing and opening of valve based on the moisture content in the field.

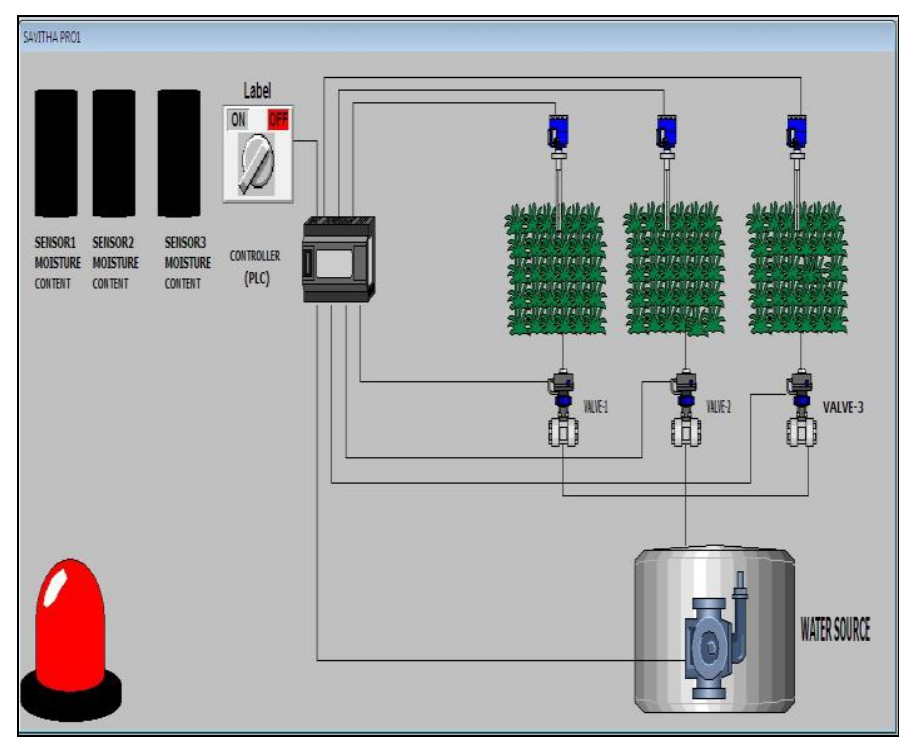

Fig -8: SCADA screen of the working model having less moisture
In this fig. 8 the moisture content of the 3 field is very less so that the valves are opened and water is pumped to all the 3 fields.

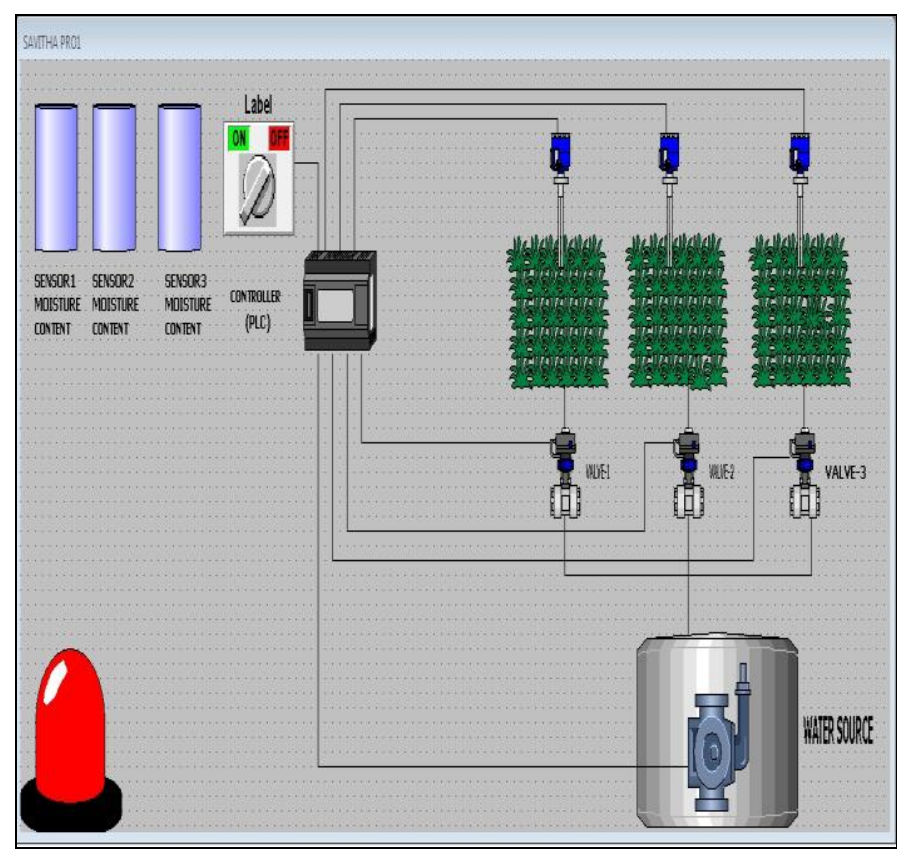

Fig -9: SCADA screen of the working model having high moisture

In this fig. 9 the moisture content of the 3 field is high so that the valves are closed and hence water is not pumped from the tank.

\section{CONCLUSION}

In future, the resources like water and electricity will be vanished unless and until the usage of renewable energy and the modern technology is implemented to save water and increase the productivity of crops. This project has a tremendous scope for future in saving water and electricity. PLC and SCADA are the latest technologies that have to be implemented in application like industrial automation, robotics, power plants, and agricultural irrigation. The person can monitor and control the irrigation system through personal computer with the help of supervisory control and data acquisition unit. 


\section{International Journal of Engineering Applied Sciences and Technology, 2019 \\ Vol. 4, Issue 2, ISSN No. 2455-2143, Pages 201-205 \\ Published Online June 2019 in IJEAST (http://www.ijeast.com)}

\section{REFERENCE}

[1] Shiraz Pasha B.R. et al,(2014) "Microcontroller Based Automated Irrigation System", The International Journal Of Engineering And Science (IJES), Vol. 3, Issue 7, pp. 06-09, June 2014.

[2] LaxmiShabadi et al,(2014) "Irrigation Control System Using Android and GSM for Efficient Use of Water and Power", International Journal of Advanced Research in Computer Science and Software Engineering, Vol. 4, Issue 7, July 2014.

[3] R.Suresh et al,(2014) "GSM based Automated Irrigation Control using Raingun Irrigation System", International Journal of Advanced Research in Computer and Communication Engineering Vol. 3, Issue 2, February 2014.

[4] Karan Kansara et al,(2015) "Sensor based Automated Irrigation System with IOT: A Technical Review", International Journal of Computer Science and Information Technologies, Vol. 6 Issue 6 , pp. 53315333, 2015.

[5] G. Parameswaran et al,(2016) "Arduino Based Smart Drip Irrigation System Using Internet of Things", International Journal of Engineering Science and Computing, Vol. 6 Issue 5, pp. 5518 -5521, May 2016.

[6] Nikesh Gondchawar el al,(2016) "IoT Based Smart Agriculture", IJARCCE, Vol.5, Issue 6, June 2016.

[7] Sanjay Kumawat et al, "Sensor Based Automatic Irrigation System and Soil $\mathrm{pH}$ Detection using Image Processing", International Research Journal of Engineering and Technology, Vol. 4 Issue 4, pp. 3673-3675, 2017.

[8] S.Vigneshwaran et al,(2017) "IOT Based Crop-Field Monitoring And Irrigation Automation" Vol. 4, Special Issue 19, April 2017.

[9] Joaquín Gutiérrez et al,(2017) “Automated Irrigation System Using a Wireless Sensor Network and GPRS Module" IEEE Transactions On Instrumentation And Measurement,Vol. 17, 2017.

[10] Dr. A.B. Jirapure1 et al,(2018) “Automatic Smart Irrigation using Wireless Sensor Network and Raspberry Pi", International Journal of Engineering Science and Computing, Vol. 8 Issue 4, pp. 1676216763, April 2018.

[11] Shishir Bagal et al,(2018) "Arduino Based Automatic Plant Watering System", International Journal of Engineering Science and Computing, Vol. 8 Issue 3, pp. 16342-16344, March 2018.

[12] Irfan Alam et al,(2018) "A Low Cost Automated Irrigation System With Soil Moisture Sensor",
International Research Journal of Engineering and Technology, Vol. 5 Issue 5, pp. 2395-0072, 2018.

[13] R. Nageswara Rao,(2018) "Iot Based Smart CropField Monitoring and Automation Irrigation System", Second International Conference on Inventive Systems and Control (ICISC 2018), IEEE Xplore, Vol. 6 Issue 4, pp. 5386-0806, 2018. 